\title{
Cutis marmorata telangiectatica congenital: two case reports
}

\author{
Imene Ben Lagha, Soumaya Youssef Zaara, Sarra Harbaoui, Kahena Jaber, \\ Mohamed Raouf Dhaoui, Nejib Doss
}

Dermatology Department, Military Hospital of Tunis, Tunisia

Corresponding author: Dr. Imene Ben Lagha, E-mail: imenebenlagha@gmail.com

\begin{abstract}
Cutis marmorata telangiectatica congenita (CMTC), or Van Lohuizen syndrome, is a rare vascular malformation of the skin of unknown cause. We report here two cases of CMTC. We report 2 cases. Case 1: A 3 year old child had since 4 month old purple reticulated lesions with a peripheral halo of pallor, located on the limbs and the left side of the trunk. The center of the lesions became progressively atrophic and the livedo disappeared after the age of 5. Case 2: A young man of 16 year old had CMTC since he was 14 months. The lesions were located on the left side of the body. At the age of 16, he developed a venous insufficiency of the left lower extremity. It was complicated with a chronic leg ulcer above the lateral malleolus. A detailed examination and a thorough follow-up plan must be set-up in patients presenting with CMTC.
\end{abstract}

Key words: Congenital vascular malformation; Cutis marmorata telangiectatica congenital; Van Lohuizen syndrome

\section{INTRODUCTION}

Cutis marmorata telangiectatica congenita (CMTC), also called Van Lohuizen syndrome, is a rare vascular malformation of the skin of unknown cause. It is defined by the presence, mostly since birth, of localized or generalized fixed skin lesions of reticulated cutaneous vascular network. Other associated anomalies have been described like limb hypertrophy or atrophy and coexistence of ulcerations. The diagnosis is based on clinical findings. We report here two cases of CMTC.

\section{CASE REPORT}

\section{Case 1}

We report the case of a 3 year old child, born from a second degree consanguineous marriage. There was no particular family history. He was followed up in our department since he was 4 month old for purple reticulated lesions with a peripheral halo of pallor, located on the limbs and the left side of the trunk. Otherwise, no extra cutaneous abnormalities were observed. Anthropometric measurements were within the normal average and there was no asymmetry of limbs growth. The center of the lesions became progressively atrophic and the livedo disappeared after the age of 5 (Fig. 1).

\section{Case 2}

A young man of 16 year old had been followed up in our department since he was 14 months for CMTC. He was born of a non-consanguineous marriage. Birth and development history were normal. There was no history of trauma or infection or similar cases in family. The patient presented since birth fixed deep purple reticulated skin lesions with underlying atrophic changes. These lesions were located on the left side of the body: on the scalp, the forehead, the trunk and the left limbs, with an extension to the right side of the abdomen. Palms, soles and mucosa were spared. At the age of 16, the patient developed a venous insufficiency

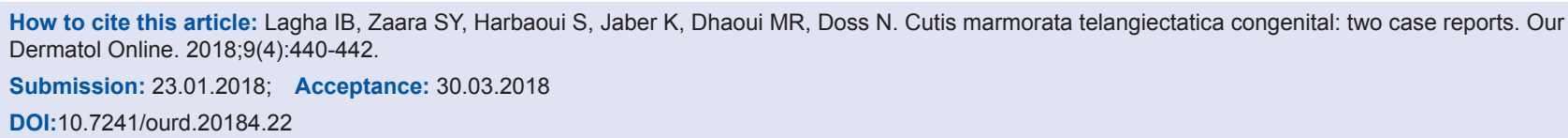




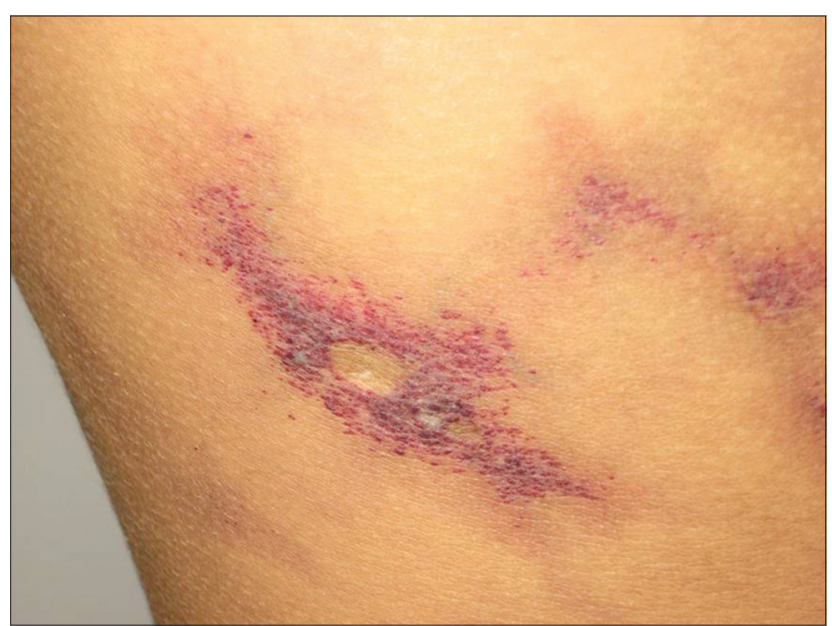

Figure 1: Red-purple vascular network with atrophic center.

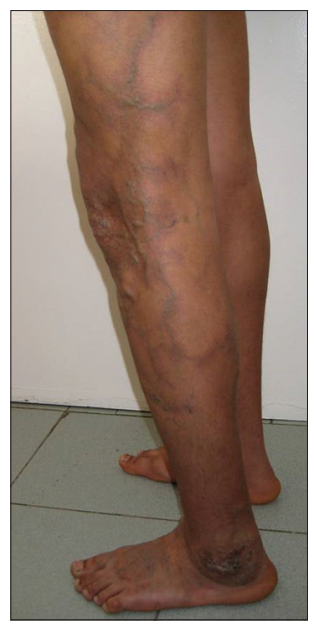

Figure 2: Varicose veins of the left leg with an ulceration above the lateral malleolus.

of the left lower extremity. It was complicated with a chronic leg ulcer above the lateral malleolus (Fig. 2).

\section{DISCUSSION}

First described by the Dutch pediatrician Van Lohuizen in 1922, CMTC is a rare congenital vascular malformation. About 300 cases have been described so far [1].

The pathogenesis is not obvious. It is considered as a sporadic disease even though a genetic etiology has been proposed in some cases. Multiple hypothesis have been suggested for the pathogenesis of this condition, such as autosomal dominant transmission with variable expressivity [2], a lethal gene surviving by mosaicism [3], a functional nervous defect [4], or a functional malformation of the terminal blood vessels [5]. A female predominance have been noticed in the literature with a more likely generalized distribution in female [1]. Our cases were both male and with a localized disease since the lesions covered less than $50 \%$ of the skin.

Clinical features are typical and the accurate diagnosis of CMTC can be made based upon a careful physical examination. Mostly, the lesions are present at birth, as it was described in our cases. Cutaneous findings in CMTC include a purple reticulate vascular network, similar to physiologic cutis marmorata. However, these lesions are persistent in CMTC and do not disappear with local warming [6]. Other skin changes include phlebectasia, telangiectasia and hyperkeratosis. Atrophy and ulceration may be present at first or appear later [1]. In our first case, atrophy appeared progressively. Our second case developed a leg ulcer at the age of 16. The distribution of lesions may be generalized or localized. They involve especially the legs and the trunk. A demarcation at the midline of the abdomen is very commonly observed [7]. Additional vascular anomalies were frequently reported such as port-wine stains, angiokeratoma and hemangioma [6].

Extracutaneous anomalies have been reported in more than $50 \%$ of patients with CMTC [1]. Asymmetric limb hypertrophy or atrophy is the most common anomaly associated with CMTC [4]. Skeletal defects such as hip dysplasia, club foot, syndactyly may be observed. Ocular anomalies may also be associated, particularly glaucoma [3]. Neurological concomitant abnormalities have also been reported. Particularly worthy of mention here is macrocephaly which was oft-times described in CMTC patients. This fact led to the individualization of a CMTC subtype called macrocephaly-cutis marmorata telangiectatica congenital in 1997 [8].

CMTC can be confused with several disorders which present with a reticular vascular network. The most common one is physiological cutis marmorata mentioned earlier. Other differencial diagnoses are Adams Oliver syndrome, klippel Trenaunay syndrome and Bockenheimer's syndrome [1]. Neonatal lupus erythematous can present with lesions similar to CMTC or be revealed with CMTC. Some authors proposed the CMTC to be part of the cutaneous findings in neonatal lupus erythematous [9]. Persisting cutis marmorata in children with Down syndrome, de Lange syndrome, Divry-Van Bogaert syndrome and homocystinuria must also to be ruled out [3] 
Capillary malformation can be difficult to distinguish from CMTC. However, the association of underlying atrophy and the fading color with time are observed only in CMTC [6].

Diagnostic criteria for CMTC have been suggested by Kienast and Hoeger in 2009. They proposed that the presence of three major criteria (congenital reticular erythema, Absence of venectasia and unresponsiveness to local warming) and two of five minor criteria (Fading of erythema within two years, telangiectasia, port wine stain, ulceration and atrophy within affected area) is sufficient for diagnosis [10].

The prognosis is usually good with improvement during the first years of life [1]. In our first case, we noted a regression of the reticular pattern within 5 years. However, in the second case, the evolution was marked by the onset of a venous insufficiency and a chronic ulcer of the affected leg. Thus, in case of non-regressive lesions, we suggest that a Doppler ultrasound should be performed every 3 to 4 years in patients with CMTC. Furthermore, patients with facial CMTC lesions should have an ophthalmological examination. Other investigations should consist on skeletal and neurological examination and screening for developmental delay and macrocephaly.

\section{CONCLUSION}

Even though CMTC is a benign cutaneous disease with good prognosis, we should be aware of the association of more serious anomalies. Thus, a detailed examination must be performed and a thorough follow-up plan must be set-up.

\section{Consent}

The examination of the patient was conducted according to the Declaration of Helsinki principles.

\section{REFERENCES}

1. De Maio C, Pomero G, Delogu A, Briatore E, Bertero M, Gancia P. Cutis marmorata telangiectatica congenita in a preterm female newborn: case report and review of the literature. Pediatr Med Chir. 2014;36:90.

2. Lunge SB, Mahajan P. Cutis marmorata telangiectatica congenita restricted to both breasts in a young female. Dermatol Pract Concept. 2014;4:89-92.

3. Ponnurangam VN, Paramasivam V. Cutis marmorata telangiectatica congenital. Indian Dermatol Online J. 2014;5:80-2.

4. Bormann G, Wohlrab J, Fischer M, Marsch WC. Cutis Marmorata Telangiectatica Congenita: laser Doppler Fluxmetry Evidence for a functional nervous defect. Pediatr Dermatol. 2001;18:110-3.

5. Baspinar O, Kervancioglu S. Repeated cutdown intervention in cutis marmorata telengiectatica. Indian Pediatr. 2006;43:369-70.

6. Levy R, Lam JM. Cutis marmorata telangiectatica congenita: a mimicker of a common disorder. CMAJ. 2011;183:249-51.

7. Matic A, Pricic S, Matic M, Velisavljev Filipovic G, Ristivojevic A. Cutis marmorata telangiectatica congenita in a preterm newborn - Case report and literature review. Iran Red Crescent Med J. 2012;14:578-83.

8. Gonzalez ME, Burk CJ, Barbouth DS, Connelly EA. Macrocephalycapillary malformation: a report of three cases and review of the literature. Pediatr Dermatol 2009;26:342-6.

9. Baline $\mathrm{K}$, Benchikhi $\mathrm{H}$. Cutis marmorata telangiectatica congenita revealing neonatal lupus. Pan Afr Med J. 2014;18:339.

10. Kienast AK, Hoeger PH. Cutis marmorata telangiectatica congenita: a prospective study of 27 cases and review of the literature with proposal of diagnostic criteria. Clin Exp Dermatol. 2009;34:319-23.

Copyright by Imene Ben Lagha, et al. This is an open-access article distributed under the terms of the Creative Commons Attribution License, which permits unrestricted use, distribution, and reproduction in any medium, provided the original author and source are credited.

Source of Support: Nil, Conflict of Interest: None declared. 